rats, monkeys, and guinea pigs was not observed in this fish. This agrees with the results of Waleszek \& Abood (1956), in which reserpine reduced aggressive behavior in fighting fish, and also with the results of Haralson \& Clement (1968), in which reserpine produced the PRE in the African mouthbreeder, in both instances without noticeable sedation.

Quantitative results and visual observation of the behavior of Ss indicate that the CS produced suppression at its onset in both control and experimental Ss, as it did in Rescorla's (1968) rats. The effect of reserpine on conditioned suppression in this study, therefore, is on the rate of recovery from the suppressive effect of CS.

\section{REFERENCES}

BLACKMAN, D. Effects of response pacing on conditioned suppression. Quarterly Joumal of Experimental Psychology, 1967, 19, 170-174.

BRADY, J. Assessment of drug effects on emotional behavior. Science, 1956, 123, 1033-1034.

COLE, J. O. Behavior toxicity. In L. Uhr and J. Miller (Eds.), Drugs and behavior. New York: Wiley, 1960. Pp. 166-183.

DAVIS, $H$. Conditioned suppression: A survey of the literature. Psychonomic Monograph Supplements, 1968, 2(14, Whole No. 30).

GELLER, I. Conditioned "anxiety" and punishment effects on operant behavior of goldfish (Carassius auratus). Science, 1963, 141, 351-353.

GELLER, I. Conditioned suppression in goldfish as a function of shock reinforcement schedule. Journal of the Experimental Analysis of Behavior, 1964, 7, 345-349.

HARALSON, J., \& CLEMENT, J. Reserpine and the partial reinforcement effect in the fish Tilapia $H$. macrocephala. Psychological Reports, 1968, 22, 1057-1064.

HARALSON, J., GILLMAN, C., \& RALPH, G. Interaction between effort and partial reinforcement in free-oeprant response of rats and fish. Psychological Reports, 1965, 16, 761-768.

HARALSON, J., \& RALPH, G. A further improvement in the automatic dispensing of live food for fish. Journal of the Experimental Analysis of Behavior, 1966, 9, 153-154.

KELLER, D., \& UMBREIT, w. Chemically altered "permanent" behavior patterns in fish and their cure by reserpine. Science, 1956, $124,407$.

KELLOGG, W. Galvanotropism as an avoidance response. Journal of Comparative \& Physiological Psychology, 1958, 51, 652-657.

KINNARD, W., ACETO, M., \& BUCKLEY, J. The effects of certain psychotropic agents on the CER behavior pattern of the albino rat. Psychopharmacologia, 1962, 3, 230.

LYON, D. Conditioned suppression: Operant variables and aversive control. Psychological Record, 1968, 18, 317-338.

RAY, $O$. Tranquilizer effects on conditioned suppression. Psychopharmacologia, 1964, 5, 136-146.

RESCORLA, R. Probability of shock in the presence and absence of CS in fear conditioning. Journal of Comparative \& Physiological Psychology, 1968, 66, 1-5.

VALENSTEIN, $\mathrm{E}$. The effect of reserpine on the conditioned emocional response in the guinea pig. Joumal of the Experimental Analysis of Behavior, 1959, 2, 219-225.

WALASZEK, E., \& ABOOD, L. Effect of tranquilizing drugs on fighting response of Siamese fighting fish. Science, 1956, 124, 440-441.

WEISKRANTZ, L., \& WILSON, W. Effect of reserpine on learning and performance. Science, 1956, 123, 1116-1118.

YAMAHIRO, R., BELL, E., \& HILL, H. The effects of reserpine on a strongly conditioned emotional response. Psychopharmacologia, 1961, 2, 197-202.

\section{NOTES}

1. Now at the University of Washington.
2. Now at State University of New York at Stonybrook.

3. This horizontal placement was suggested to us by Robert A. Stewart.

4. Serpasil used in this experiment was donated by Ciba Pharmaceutical Co.

5. S probably felt less pain as a function of the lowered voltage gradient produced by this attitude. However, the horizontal position of the electrodes probably produced fewer extraneous effects on the data than the vertical placement used by Geller. Both effects can be eliminated by using two pairs of vertical electrodes mounted at right angles to each other and alternately activated by a commutator at $1 / 2$-sec intervals. Substitution of a grid scrambler or a bi-stable vibrator should prove superior to the commutator.

\title{
Peripheral shock, implanted electrodes and artifactual interactions: A renewed warning ${ }^{1}$
}

\section{J. S. SCHWARTZBAUM and JOHN W. GUSTAFSON, 2 University of Rochester, Rochester, N.Y. 14627}

Peripheral shock delivered to animals with intracranial electrodes may induce flows of current through the electrodes that effectively stimulate the brain. This cross talk relates to the adequacy with which shock and electrode circuits are "isolated" from ground. Capacitive coupling to ground, which is less easy to measure, may be as important as resistive connections. Such artifactual brain stimulation may have motivational properties that attenuate aversive properties of the shock. It may also give rise to afterdischarges that are not evident behaviorally. This problem of cross talk cannot be ignored in research with peripheral shock of animals with intracranial electrodes.

This note is prompted by a recent paper (Brunner, Rossi, Stutz, \& Roth, 1970) that deals with the retrograde effects of brain stimulation on shock-motivated behavior The study is not atypical procedurally of other work that has appeared in the literature, and our comments are not directed exclusively to it. These studies contain a potential artifact, which, in the absence of additional information, makes it virtually impossible to evaluate their findings. The artifact in question can have major behavioral consequences. We would like to reemphasize a warning that we offered several years ago (Schwartzbaum \& Donovick, 1965) and present some additional observations on the consequences of the artifactual interaction to which we referred.

In experiments involving peripheral shock of animals with implanted electrodes, cross talk may occur between the shock and electrode circuit, whether used for stimulation or recording, unless certain precautions are observed. This interaction results essentially from the use of shock circuits that are resistively or capacitively referred to ground and from the availability of ground connections through the electrode circuit. Although the problem can be stated simply, it is not always recognized in practice since isolation from ground is a relative matter, and one typically does not assess capacitive coupling to ground. If a shock source is inadequately "isolated" from ground and if there exists resistive or capacitive coupling to ground in the electrode circuit, then application of shock to the animal's body may induce a flow of current through the electrode circuit. Elements in the electrode circuit may basically offer a ground connection that parallels that of the shock circuit. The flow of current will depend upon shock parameters and the ground impedance of the two circuits.

Capacitive coupling to ground represents a subtle problem. It may arise, e.g. through capacitance between a cable and grounded shield, as often used for electrode leads. The reactance offered by such a coupling relates to its capacitance and the frequency parameters of the imposed voltage. With 60-cycle ac shock or even pulsed dc shock, assuming inadequate is olation from ground, electrophysiologically significant flow of current may be generated through 


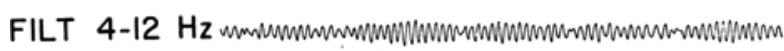
LT PVH Lim

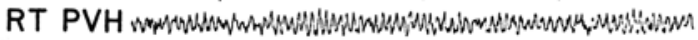

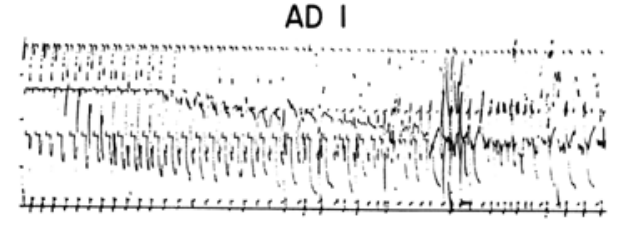

POST-ICTAL DEPRESSION

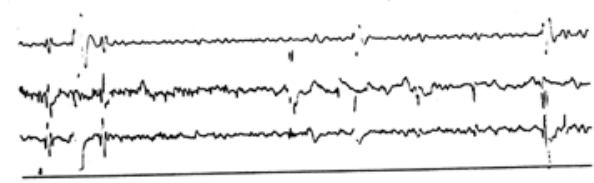

$A D 2$

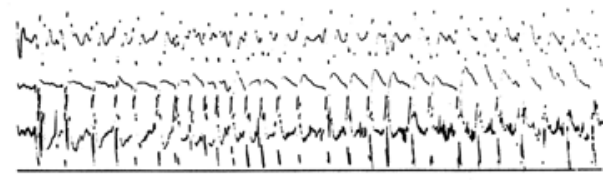

7 MIN POST

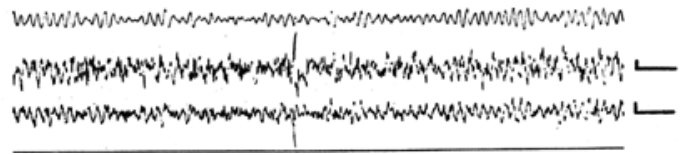

Fig. 1. Example of afterdischarges evoked bilaterally in the posterior-ventral hippocampus (PVH) by peripheral shock through grid floor bars. Top trace: filtered theta activity of right PVH. Bottom trace: flash stimulus marker. Calibration: 100 micro V, 1 sec.

electrode circuits via such capacitive coupling even if all resistive connections to ground have been eliminated.

The net effect of such artifactual interactions is simultaneous stimulation of the brain through implanted electrodes by peripheral shock. At the very least, this cross talk may serve to scramble normal electrophysiological activity. It may give rise to rewarding stimulation that may effectively counteract or attenuate punishing properties of the shock (Cox \& Valenstein, 1965; Schwartzbaum \& Donovick, 1965); this is especially true of 60-cycle sinusoidal shock, since reward thresholds for such stimulation are relatively low. Such cross talk may also set off afterdischarges in structures with high seizure susceptibility, such as the amygdala or hippocampus. This latter possibility is especially serious since the occurrence of afterdischarges may not be detected overtly! The following example illustrates this point.

Rats were implanted with concentric bipolar leads in the posterior-ventral part of the hippocampus and elsewhere, and their EEG activity and averaged evoked responses were studied in the freely moving state during a CER procedure in which a series of flashes of light were terminated with a 1.0 -sec shock to grid-floor bars. The intensity of shock was adjusted to evoke aversive responses. We used two different shock sources: a 60-cycle ac source of conventional design (step-up transformer with high internal resistance in series with the output) and a constant-wattage solid-state device with grid scrambler that supplied dc pulses. Neither of these shock sources was adequately isolated from ground. But we assumed that since precautions were taken to eliminate any resistive coupling to ground in the electrode circuits during the grid shock, no cross talk would result. Our assumption was wrong. As shown in Fig. 1, the grid shock evoked massive afterdischarges in the hippocampus, which persisted on a recurring basis for at least $120 \mathrm{sec}$. This was a reproducible phenomenon in this and other animals and did not relate to some preexisting seizure focus. Significantly, however, the animal displayed no obvious overt signs of seizure activity during the massize hippocampal afterdischarges. It moved slowly about the test chamber, as if exploring, and only occasionally showed slight lurching to the side. One would have been hard pressed to judge whether any dysfunction existed by simply observing the animal, although we did not examine its reactivity to handling. Under other conditions, less sustained afterdischarges might occur which would increase the difficulty in recognizing their existence. All of this cross-talk effect resulted from capacitive coupling of shielded electrode leads in which the shields remained grounded. The problem was readily solved through use of an isolation transformer in the shock circuit. It could also have been corrected by disconnecting shield circuits to ground during grid shock.
However, the fact remains that such artifactual interactions may not always be recognized. What one assumes to be a retrograde experimental treatment may be quite different. If afterdischarges are evoked, then other issues arise (Lidsky, Levine, Kreinick, \& Schwartzbaum, in press). What further interactions may occur with additional brain stimulation is even more horrendous to contemplate. Control treatments may not be adequate for the conclusions drawn from the data. Unless researchers can provide explicit assurance that such cross talk has not occurred, one must simply suspend judgment on their findings.

\section{REFERENCES}

BRUNNER, R. L., ROSSI, R. R., STUTZ, R. M. \& ROTH, T. G. Memory loss following posttrial electrical stimulation of the hippocampus. Psychonomic Science, 1970, 18, 159-160.

COX, V. C., \& VALENSTEIN, E. S. Attenuation of aversive properties of peripheral shock by hypothalamic stimulation. Science, 1965, 149 , 323-325.

LIDSKY, T. I., LEVINE, M. S., KREINICK, C. J., \& SCHWARTZBAUM, J. S. Retrograde effects of amygdaloid stimulation on conditioned suppression (CER) in rats. Journal of Comparative \& Physiological Psychology, in press.

SCHWARTZBAUM, J. S., \& DONOVICK, P. J. An artifact in the use of brain stimulation with shock-motivated behavior. Psychonomic Science, 1965, 2, 183-184.

$$
\text { NOTES }
$$

1. This study was supported by Grant MH-14594 from the National Institute of Mental Health.

2. NIH Predoctoral Fellow. 